use of antidepressants in primary care, and more urgent attention by NHS planners, should help to restore that confidence.

Andre Tylee professor of primary care mental health Health Services Research Department, Institute of Psychiatry, London SE5 8AF

\section{Roger Jones Wolfson professor of general practice}

Department of General Practice and Primary Care, GKT School of Medicine, London SE11 6SP

(roger.jones@kcl.ac.uk)

Competing interests: None declared.

1 Blair T. Message from the prime minister. In: Dawson A, Tylee A, eds Depression: social and economic timebomb. BMJ Publishing Group, London, 2001:ix.

2 Shepherd M, Cooper B, Brown AC, Kalton G. Psychiatric illness in general practice. London: Oxford University Press, 1966.

3 Goldberg D, Huxley P. Common mental disorders. A biosocial model. London: Routledge, 1992

4 Pirkis J, Burgess P. Suicide and recency of health care contacts. $\mathrm{Br} J$ Psychiatry 1998;173:462-74.
5 Lépine JP, Gastpar M, Mendlewicz J, Tylee A. Depression in the community: the first pan-European study DEPRES (Depression Research in nity: the first pan-European study DEPRES (Depression
Europe Society). Int Clin Psychopharmacol 1997;12:19-29.

6 Thompson C, Kinmonth AL, Stevens L, Peveler RC, Stevens A, Ostler KJ, et al. Effects of clinical-practice guideline and pradtice-based education on detection and outcome of depression in primary care: Hampshire Depression project randomised controlled trial. Lancet 2000;355:185-91.

7 Walters P, Tylee A. In: Maj M, Lopez-Ibor J, Sartorius N, Sato M, Okasha A, eds. Early detection and management of mental disorders. World Psychiatric Association. Chichester: John Wiley, 2005.

8 Bushnell J on behalf of the MaGPIe Research Group. Frequency of consultations and general practitioner recognition of psychological symptoms. Br J Gen Pract 2004;54:838-42.

9 Priest RG, Vize C, Roberts A, Tylee A. Lay people's attitudes to treatment of depression: results of opinion poll for Defeat Depression Campaign of depression: results of opinion poll for Deft

10 Symons L, Tylee A, Mann A, Jones R, Plummer S, Walker M, et al. Improving access to depression care: descriptive report of a multi-disciplinary primary care pilot service. Br J Gen Pract 2004;54: 679-83.

11 Proudfoot J, Ryden C, Everitt B, Shapiro D, Goldberg D, Mann A, et al. Clinical effectiveness of computerised cognitive behavioural therapy for anxiety and depression primary care. A randomized controlled trial. $\mathrm{Br} J$ Psychiatry 2004; 185:46-54.

12 Enhanced Services Specification for depression under the new GP contract: a commissioning guidebook. National Institute for Mental Health in England. $\mathrm{http} / / / \mathrm{kc}$.nimhe.org.uk/index.cfm?fuseaction = Group.viewPost\&intPost $\mathrm{ID}=20733$ \&intGroupID = 209 (accessed 22 Mar 2005).

\title{
Aortic stenosis
}

\section{Is common, but often unrecognised}

$\mathrm{A}$ ortic valve disease is common. In Western populations, about $25 \%$ of people aged over 65 have aortic sclerosis, and 3\% over 75 have severe stenosis. ${ }^{1}$ In 2003, 6028 aortic valve operations were done in Britain and Ireland compared with 25277 for isolated coronary disease. ${ }^{2}$ Despite this the diagnosis may often be missed. Probably half are still diagnosed at postmortem examination, and $5 \%$ of operations are performed at end stage. ${ }^{3}$ Unrecognised aortic stenosis is an important cause of anaesthetic and obstetric mortality.

The overwhelming cause of aortic valve disease in Europe is calcific degenerative disease, and about 2\% of the population have congenitally bicuspid aortic valves. Rheumatic disease is now rare. Stenosis is differentiated from sclerosis, when a restriction of cusp movement and a raised transaortic peak velocity are seen on echocardiography. Around $16 \%$ of patients with sclerosis progress to stenosis in seven years. ${ }^{4}$ The early lesions of calcific degenerative disease resemble atheroma of the coronary artery. Many of the risk factors for aortic stenosis are common to other atherosclerotic processes, and one would expect treatment with statins to reduce the rate of progression. However, a recent, small, randomised study of atorvastatin was negative. ${ }^{5}$ Aortic valve disease is also a marker for coronary disease and coronary events. The incidence of myocardial infarction is $6.0 \%$ over five years in septuagenarians with normal aortic valves, $8.6 \%$ with aortic sclerosis, and $11.3 \%$ with aortic stenosis. ${ }^{7}$ Current randomised trials, including the simvastatin and ezetimibe in aortic stenosis (SEAS) study will test the effect of lipid lowering on both cardiovascular events and the progression of aortic stenosis.

One reason for failing to make a diagnosis is that the clinical signs can be difficult to interpret. Although recommended indications for echocardiography grade of the murmur may not always reflect the severity of the disease. ${ }^{9}$ All typical textbook guides are of limited value, particularly when the examiner is inexperienced or does not have specialist training in cardiology. ${ }^{9}$ A normal or high blood pressure with a normal pulse pressure is often used to dismiss the possibility of severe aortic stenosis. However, only $7 \%$ of patients referred for surgery have a pulse pressure of less than $35 \mathrm{~mm} \mathrm{Hg}$, and the second sound and carotid upstroke may also be normal. ${ }^{9}$ The signs of aortic stenosis were originally described in young patients when the dominant cause was rheumatic disease. Calcific degenerative disease in older people is often associated with systemic hypertension, coronary disease, and arteriosclerosis, all of which can confound the effects of aortic stenosis on the circulation and therefore modify the clinical signs.

Another reason for failing to recognise aortic stenosis is that most patients have a long asymptomatic period and may therefore not seek medical attention. During this period, the mortality is low. Guidelines recommend surgery when symptoms develop since mortality then rises sharply. The median survival is 4.5 years with exertional chest pain, 2.6 years with exertional dizziness, and one year with overt heart failure. ${ }^{10}$ Around $10-15 \%$ of patients die soon after the onset of symptoms, giving little time to make the diagnosis and organise surgery.

The aim should therefore be to make the diagnosis while the patient is still apparently asymptomatic. For those who are truly asymptomatic, echocardiography is increasingly being used to predict the likely onset of symptoms so as to plan elective surgery. The use of blood testing for brain natriuretic peptide is also being explored. Most patients should also have a treadmill exercise test because unexpected symptoms will show up in up to half of them. ${ }^{11}$ Symptoms may not be apparent in daily life because the patient may be sedentary or 
may limit exercise to avoid symptoms. In many centres, aortic stenosis is still regarded as a contraindication rather than an indication for exercise testing.

In view of the frequency and clinical importance of silent aortic stenosis, we should consider national screening strategies and ways of ensuring that patients with noteworthy murmurs have echocardiography. We need also to develop specialist clinical experience in aortic but also other types of valve disease since diagnostic formulations, treatment plans, and surgery may often be difficult. Aortic valve disease is under-recognised politically as well as clinically. It is not yet covered properly a national strategy document from the National Institute for Clinical Excellence (NICE) or any other organisation. As our population ages, the prevalence of aortic stenosis inevitably rises. By 2020, about 3.5 million of a total population of 54 million in England can be expected to have aortic sclerosis and 150000 to have severe aortic stenosis. ${ }^{12} \mathrm{We}$ should prepare for this epidemic now.

John Chambers consultant cardiologist

Guy's and St Thomas' Hospitals, London SE1 7EH

(jboydchambers@aol.com)

\section{Competing interests: None declared.}

1 Lindroos M, Kupari M, Heikkala J, Tilvis R. Prevalence of aortic valve abnormalities in the elderly: an echocardiographic study of a random abnormalities in the elderly: an echocardiographic stud
population sample. J Am Coll Cardiol 1993;21:1220-5.

2 Keogh BE, Kinsman R. Fifth national adult cardiac surgical database report. London: Society of Cardiothoracic Surgeons of Great Britain and Ireland, 2003

3 Connolly HM, Oh JK, Orszulak TA, Osborn SL, Roger VL, Hodge DO, et al. Aortic valve replacement for aortic stenosis with severe left ventricular dysfunction. Prognostic indicators. Circulation 1997;95:2395-400.

4 Cosmi JE, Tunick PA, Rosenzweig BP, Freedberg RS, Katz ES. The risk of development of aortic stenosis in patients with benign' aortic valve thickening. Arch Int Med 2002;162:2345-7.

5 Novaro GM, Tiong IY, Pearce GL, Lauer MS, Sprecher DL, Griffin BP. Novaro GM, Tiong IT, Pearce GL, Lauer MS, Sprecher DL, Griffin BP. Effect of hydroxymethylglutaryl coenzyme A reductase inhibitors on
progression of calcific aortic stenosis. Circulation 2001;104:2205-9.

6 Progression of calcific aortic stenosis. Circulation 2001;104:2205-9. Intensive lipid-lowering therapy does not halt the progression of calcific aortic stenosis. Circulation 2004 (abstract)

7 Otto CM, Lind BK, Klitzman DW, Gersh BJ, Siscovick DS. Association of aortic valve sclerosis with cardiovascular mortality and morbidity in the elderly. N Engl J Med 1999;341:142-7.

8 Cheitlin MD, Alpert JS, Armstrong WF, Aurigemma JP, Beller GA, Bierman FZ, et al. ACC/AHA guidelines for the clinical application of echocardiography: executive summary J Am Coll Cardiol 1997:29:862-79.

- Das P, Pocock C, Chambers J The patient with a systolic my 29:862-79. Das P, Pocock C, Chambers J. The patient with a systolic murmur: severe
aortic stenosis may be missed during cardiovascular examination. Quart J

10 Horstkotte D, Loogen F. The natural history of aortic valve stenosis. Eur Heart J 1988;9(suppl E):57-64.

11 Carabello BA. Aortic stenosis. N Engl J Med 2002;346:677-82.

12 Government Actuary's Department. 2003 figures. www.gad.gov.uk/ Population/index.asp (accessed 4 Mar 05).

\section{Long term sickness absence}

\section{Is caused by common conditions and needs managing}

$\mathrm{S}$ ickness absence is a major public health and economic problem. In 2003, 176 million working days were lost; up 10 million on the previous year. ${ }^{1}$ Each week 1 million people report sick, 3000 of whom will still be away from work at six months. ${ }^{2}$ Only $20 \%$ of people receiving incapacity benefit for more than six months will return to work in the following five years. ${ }^{3}$ The costs are enormous. Each year, £13bn (\$25bn; €19bn) are spent on benefits such as incapacity benefit, and the cost to industry is at least $£ 11 \mathrm{bn} .^{4}$ Long term sickness absence contributes disproportionately to these figures. Although they constitute only a small fraction of absence episodes, longer absences comprise more than a third of total days lost and up to $75 \%$ of absence costs. ${ }^{12}$ Longer absences are associated with a reduced probability of eventual return to work and subsequent economic and social deprivation.

The government is increasingly aware of the issue and has made the reduction of work related ill health and disability, and resulting absence, a top priority. ${ }^{5}$ Recently a major overhaul of the incapacity benefit system was announced, in an attempt to remove some of the financial incentives for remaining incapacitated and some early results of vocational rehabilitation programmes have been filtering through. These are primarily aimed at people who have already been in the benefit system for a long time. Moving the agenda further towards primary prevention, the recent white paper, Choosing Health, included an important, but somewhat overlooked, chapter on work and health proposing several policy programmes. ${ }^{4}$
What medical conditions are producing such levels of morbidity? It might be expected that only severe illnesses would lead to such marked reduction in function, but in fact most long term absence is due to common conditions that, for whatever reason, fail to improve sufficiently. Until recently the most common causes were musculoskeletal disorders, in particular low back pain. In 1994-5, 194000 new awards of social security benefits were made for back related incapacities, accounting for more than one in seven such awards. ${ }^{6}$ However, since then awards for back conditions have dropped by $42 \%{ }^{6}$

Over the same decade the contribution of psychiatric disorders to sickness absence has increased markedly, and surveys have shown a doubling in the numbers of people reporting stress that was caused or made worse by their work. ${ }^{7}$ Mental and behavioural disorders now account for more incapacity benefit claims than musculoskeletal disorders. ${ }^{3}$ This has occurred despite no apparent increase, except for alcohol dependence, in their prevalence. ${ }^{8}$ In light of this, the Health and Safety Executive has recently produced guidelines on the management of stress at work, based on current understanding of occupational factors such as job strain. ${ }^{9}$

Several recent government initiatives have been introduced to tackle the low employment rates among people with severe mental illness. These include individual placement support, return to work being included within patient care plans, and a strategy against stigma that is based on the social exclusion unit's recommendations. ${ }^{4}$ However, it is common men- 